\title{
El periódico Palabra Socialista (1912-1914) y los comienzos de la disidencia marxista en el PS
}

\author{
Hernán M. Díaz \\ UBA \\ hernandiaz59@gmail.com
}

El periódico quincenal Palabra Socialista tuvo un papel de primer orden en la constitución de la oposición de izquierda dentro del Partido Socialista argentino, pero su consulta estaba (o está) prácticamente vedada a los investigadores. Mencionado ocasionalmente en textos de la época o en trabajos historiográficos posteriores, sus ejemplares no se podían ubicar en los repositorios y archivos conocidos de la Argentina. En el Cedinci, hasta el momento de escribir este texto, no figuraba en catálogo.

Hemos encontrado una colección aparentemente completa en la Bibliothèque de Documentation Internationale Contemporaine (Universidad de Nanterre, Francia), microfilmada en negativo, lo cual nos da la oportunidad para hacer un relevamiento de sus ideas y analizar de qué manera se fue constituyendo un núcleo de jóvenes marxistas al interior de un partido tildado por ellos como reformista y practicista. De hecho, el núcleo que se consolida en torno de Palabra Socialista y más adelante del Comité de Propaganda Gremial es el primer grupo en la Argentina constituido de manera orgánica alrededor de las ideas de Marx y Engels. Sin quitar mérito a los internacionalistas de la década de 1870, al defensor solitario del marxismo que fue Germán Avé Lallemant, a los rebeldes verbales de La Montaña o a tantos dentro y fuera del partido que defendieron las ideas de Marx, este grupo que en 1918 terminará fundando el Partido Socialista Internacional es el primero que actúa orgánicamente como un nucleamiento de militancia obrera y marxista, con el objetivo colectivo de transformar la fisonomía del socialismo en la Argentina para marchar hacia una dictadura del proletariado.

El Partido Socialista argentino hacia el Centenario, ya con veinte años de actividad, no habia sabido construirse un norte definido, ni siquiera en función de aquel aspecto que el equipo liderado por Juan B. Justo consideraba su eje de trabajo, confeso o no: el reformismo parlamen-

(Archivos, año III, $\mathrm{n}^{\circ}$ 6, pp. 95-113) 
tario. Su política con respecto al movimiento obrero había significado una derrota tras otra: superado por el anarquismo, el llamado "sindicalismo revolucionario" se llevó en 1906 la mayor parte de los obreros del partido. La política parlamentaria tuvo su momento de gloria en 1904 con el logro de una banca para Alfredo Palacios, pero ese éxito no se repetiria hasta 1913, ya bajo el amparo de la ley Sáenz Peña. Orgulloso de la pertenencia a un movimiento internacional en ascenso, el PS sin embargo no exhibía ningún vigor teórico y paulatinamente se había ido recostando cada vez más en un democratismo que no ocultaba sus raices confusamente liberales.

La profunda derrota que experimenta el movimiento obrero en el Centenario da pie a que un sector de jóvenes del partido, que han vivido o protagonizado las encendidas luchas de la década pasada, saquen un balance negativo de las derivas reformistas del partido de Justo. En un país como la Argentina, donde el proletariado se mantiene en un nivel de pobreza que hace frecuente la comparación de la Argentina con Rusia o España, y donde la opción represiva es la apuesta que prevalece en la filosofia del Estado, el parlamentarismo y el democratismo tienen escaso margen y no saben ofrecer logros, salvo simbólicos. En coincidencia con la diferenciación, en muchos países europeos, de diversas tendencias dentro de los partidos de la Segunda Internacional, un núcleo de jóvenes emprende un camino de crítica al interior del Partido Socialista de la Argentina, con la intención expresa de vincular de una manera orgánica las ideas socialistas con el movimiento obrero.

Esta tendencia, que mostrará su fisonomía más organizada y definida con la creación en 1918 del Partido Socialista Internacional, tiene su acta de nacimiento con el periódico que analizamos.

\section{Algunos elementos fácticos}

El periódico Palabra Socialista, si bien no se convirtió en un medio de larga duración, superó en permanencia temporal a la mayoría de los pequeños emprendimientos gráficos en el socialismo argentino. Se publicó con una extraordinaria regularidad cada 15 días (el $1^{\circ}$ y el 15 de cada mes), durante casi dos años completos: el primer número salió a la calle el 14 de julio de 1912 y el último (al menos en la colección consultada) es del 15 de mayo de 1914. Solamente se saltean una quincena en febrero de 1913 y otra en enero de 1914, por alguna circunstancia estival que no explican. Todos sus ejemplares contaban con 8 páginas, salvo el número especial del $1^{\circ}$ de mayo de 1913 ( $\left.\mathrm{n}^{\circ} 18\right)$, con 16 páginas, que conmemoraba la jornada de lucha de los trabajadores.

Gráficamente era un producto medianamente bueno, con algunas dificultades tipográficas y de corrección, sobre todo al principio. Oca- 
sionalmente incluía algunas fotografias o alegorias. Un miembro de la redacción, Pablo Chanussot, actuó a menudo como traductor de textos del francés al castellano. Otro colaborador asiduo, Cornelio Thiessen, traduce textos del inglés y del alemán, y también envía artículos donde se evidencia el conocimiento directo de las publicaciones en esos idiomas. En un número recogen noticias y artículos de Rusia y de Bulgaria traducidos por N. Kazandjieff, quien tendrá después una larga militancia en el Partido Comunista, dirigiendo la Agrupación Comunista Búlgara de Buenos Aires.

En muchos momentos, particularmente en el segundo año de edición, el estilo de los artículos tiene un tono sarcástico que parece salido de la pluma de Juan Ferlini Guillán, frecuente colaborador y por momentos secretario de redacción. La mordacidad y las ironías son habituales en quien años después se convertiría en el primer concejal del PSI, y muestran no sólo un gran manejo de la lengua castellana sino también sus amplios conocimientos librescos. Cuando ese estilo sarcástico es cuestionado por algún lector, la redacción (virtualmente, el mismo Ferlini) sale en su defensa: "Formulamos la promesa de no corregirnos, pues entendemos que hacerlo sería llevar al suicidio nuestra propia obra. Tenemos un alto concepto de la 'sátira' como elemento de crítica y no estamos dispuestos a rectificarlo" ("Actualidades", sin firma, en $n^{\circ}$ 32, 15 de diciembre de 1913).

Para solventar los gastos del periódico se crea, previo al primer número, una cooperativa específica, conformada por los siguientes integrantes: Nicolás Di Pinto, Renato D. Cozzi, José F. Grosso, Martín Casaretto, Jaime López, E. González Mellén, José F. Penelón, Alejandro Jascalevich, Julián Ducasse, Manuel Domínguez, Pedro Zibecchi, Antonio Chiaia, Manuel Freire (hijo), Juan Clerc, Fernando Guillot, Gerardo Lamenza, Pablo Chanussot, J. Garcia Fernández, Luis Miranda, Blas Feijoo, Paulino Domínguez, Vicente Fazio, Domingo Fazio, Luis León, José Vescovo y Pascual Paolini. En la redacción son nombrados inicialmente Grosso, González Mellén y Casaretto, pero habrá una alternancia significativa de redactores, cuyo detalle haremos más adelante.

La sede del periódico figura en Canning 929, pero al año siguiente se producen una serie de cambios. En primer lugar, se crea el Centro Carlos Marx, ${ }^{1}$ a partir del propio periódico y con la participación de muchos de los que formaban parte de la cooperativa o de militantes socialistas que habían colaborado con la publicación. Desde el número $21\left(1^{\circ}\right.$ de julio de 1913), Palabra Socialista hace constar bajo su nombre: "Órgano del

1. Así es nombrado este centro desde su creación en julio de 1913. Referencias posteriores lo nombran Centro de Estudios Carlos Marx o Centro de Estudios Sociales Carlos Marx, pero aquí respetaremos el nombre que figura en Palabra Socialista. 
Centro Carlos Marx". Desde agosto de 1913 la administración se traslada al local de Pedro de Mendoza 1981 (a la vez que desaparece la mención al local de Canning 929, dirigido por Pedro Zibecchi, quien además deja de firmar en el periódico) y desde febrero de 1914 figura también la dirección de la redacción en Estados Unidos 1056, renombrado local que en los años venideros sería el principal punto de irradiación de la disidencia de izquierda que en febrero de 1918 formó el PSI.

En la publicación se hace constar también la existencia de varios "agentes", que seguramente recibian por correo los ejemplares para ser distribuidos en su localidad y ocasionalmente envian colaboraciones o informaciones al periódico. La red de distribución artesanal incluía varias poblaciones hoy parte de la capital federal o del Gran Buenos Aires, pero que en aquel momento estaban distanciadas geográficamente (Villa Devoto, Lanús, Santos Lugares, Avellaneda, Ramos Mejía, Lomas de Zamora, Haedo, Wilde), pueblos o ciudades de la provincia de Buenos Aires (La Plata, Mar del Plata, Bahía Blanca, Exaltación de la Cruz, Lobos, Nueve de Julio, San Nicolás), de Santa Fe (Rosario, Rufino) y la ciudad de Córdoba. También se registra una conexión frecuente con el socialismo uruguayo y con grupos socialistas de Chile, lo cual nos informa que la militancia del comunismo argentino en el ámbito sudamericano en los años 20 (Jeifets y Jeifets, 2014), ya se podía registrar en los origenes del grupo.

No contamos con datos de tirada y tampoco el periódico ofrece una imagen clara acerca de la penetración en gremios y sindicatos. Como parece ser la tónica general en el Partido Socialista, el militante se referencia más en su centro de afiliación que en su lugar de trabajo y las noticias sindicales o de huelgas hacen poca mención a la participación de corrientes políticas y menos aún a los propios participantes del periódico.

\section{Cuestiones programáticas}

El periódico Palabra Socialista surge como iniciativa de un grupo de militantes opuestos de manera decidida a la política de la dirección del partido, a la que acusan habitualmente de "practicista", a veces de "reformista", y de abandonar la prédica del ideal del socialismo para resumirse en un oportunismo electoralista y democrático. A diferencia del periódico oficial La Vanguardia (que se va convirtiendo paulatinamente en el principal blanco de las críticas), se hace una defensa de las tesis generales del marxismo, tanto en sus nociones económicas como políticas, se reivindica la centralidad del movimiento obrero como forjador del socialismo y se reclama que el partido deje de lado su menosprecio por la lucha sindical. En ese sentido, Palabra Socialista cree representar un socialismo obrero, marxista, anticapitalista y combativo. 
La posibilidad de mejoras y de reformas en la sociedad capitalista es cuestionada constantemente en la publicación. Sólo la lucha de clases, es decir la relación de fuerzas, hará posible que una ley se aplique, se aplique mal o no se aplique. Las reivindicaciones de los trabajadores sólo podrán ser satisfechas plenamente en otra sociedad. Así debe entenderse entonces la conclusión de Elías Leyboff: "Sólo la dictadura del proletariado hará posibles las verdaderas reformas socialistas" ("E1 socialismo automático en acción", 1 de septiembre de 1913, subrayado en el original).

Declaradamente, el objetivo del periódico es generar una discusión de principios en el seno del socialismo argentino, ya que lo que observa el grupo de redactores es que la dirección homogeneíza a la organización detrás de una política reformista, y que la única manera de revertir ese derrotero es a través de la discusión abierta, serena, impersonal y principista (por ejemplo, entre muchos otros artículos, "Una nueva etapa", por Renato Cozzi, $\mathrm{n}^{\circ} 20,15$ de junio de 1913).

Cuando se realiza el XI congreso del PS, señalan "lamentables desviaciones del criterio marxista de la lucha de clases, atenuado en grado sumo, por no decir desvirtuado, en virtud del predominio de un reformismo extremo" ( $\mathrm{n}^{\circ}$ 9, 15 de noviembre de 1912). Reconocen que la dirección partidaria cuenta con una mayoría legítima y el periódico se siente parte de la minoria crítica del congreso, pero por ello mismo quieren tener el derecho a discutir lo que ellos consideran el verdadero camino del socialismo.

Aparecen algunas referencias ocasionales al revisionismo de Bernstein (al que se critica con los mismos epítetos que a la dirección del socialismo argentino), pero no se aprecia por ello un apoyo explícito a alguna otra fracción del socialismo internacional. En general prevalece una elogiosa reivindicación, poco matizada desde nuestro punto de vista, de un "socialismo europeo" que se desarrolló gracias a levantar las banderas de la lucha proletaria contra el capital y que todavia entonces, en los momentos previos a la primera guerra mundial, puede ser visto como un socialismo no esclerosado y provisto de una organización modelo. En ese sentido, el periódico parece contraponer el gran movimiento desarrollado en Europa al pequeño partido oportunista que surge en la Argentina.

A través de diferentes plumas, aparecen citados y defendidos los grandes escritores del socialismo hasta ese momento: Karl Marx, Friedrich Engels, Ferdinand de Lassalle, Grigori Plejanov, Antonio Labriola, Jules Guesde, Paul Lafargue, Karl Kautsky, Jean Jaurès. La idea que se transmite es que el socialismo europeo, como un todo, es un movimiento proletario, opuesto al capitalismo y decidido a enfrentarse a cualquier guerra si esta es declarada. Los "herejes" (críticos revisionistas o politicos 
oportunistas que aceptan cargos en gobiernos burgueses) son pocos y han sido combatidos por las direcciones oficiales o directamente expulsados. Se menciona en algún artículo la división entre marxistas y no marxistas del socialismo ruso, pero no se informa de otras tendencias similares en el resto de los países.

Desde los primeros números se realiza un seguimiento destacado del socialismo italiano, dividido por esos años en varias fracciones (ultrarreformistas, moderados, intrasigentes y revolucionarios). La revista se congratula del alejamiento de los ultrarreformistas en el congreso de Ancona (1912), y con eso se da por satisfecha en cuanto a la orientación ideológica de aquel partido. Paralelamente, se hace varias veces un elogio desmedido del viejo revolucionario Amílcare Cipriani, residente en $\mathrm{Pa}$ rís, que es de quien toman el relato del congreso, aunque la relación de Cipriani con el socialismo es bastante sinuosa. Garibaldino y comunero en el último tercio del siglo XIX, en su exilio francés se acerca más a los anarquistas y al socialismo revolucionario que al socialismo marxista. Hombre de lucha más que de doctrina, Palabra Socialista ve en él no tanto al militante marxista como al luchador que posee muchas de las cualidades que le faltan a la dirección del socialismo argentino.

Pero la idealización de la situación en Europa, si bien se puede leer en diversos artículos, no es compartida por todos los articulistas del periódico. Cornelio Thiessen parece tener una mayor conciencia de las dificultades del desarrollo de las ideas de Marx. En un artículo, en el que combate una crítica de Enrique Dickmann al marxismo, al que el dirigente del partido considera "dogmático", afirma Thiessen:

Los "dogmas" del marxismo nunca han dominado a los partidos socialistas. En Alemania los marxistas han tenido que luchar constantemente con Lassalle y su herencia; sólo en 1891 pudieron desaparecer del programa las herejías más esenciales de Lassalle. En Francia, Guesde y Lafargue sólo en los últimos años han podido consolidar las fuerzas de los guesdistas. Jaurès y sus amigos nunca han sido partidarios de Marx ni de una política de clase. En Inglaterra, los marxistas, con su veterano, constituían una minoría insignificante. Sólo en los últimos años, al aniquilarse la situación privilegiada del capital inglés, parcialmente con la acentuación de los antagonismos sociales, el "dogma" empieza a introducirse también allí. En Norte América, los Knights of Labour, la organización sin duda más inteligente del pasado, era inspirada por ideas de Henry George. El primer diario marxista de Suecia apareció en 1908; en Rusia recién en 1903 organizóse la fracción marxista del socialismo. En la Argentina, a pesar del socialismo "importado" de Engels, Plekankoff [sic], de la primera época 
de La Vanguardia, asistimos recién ahora al nacimiento de los "dogmas" en los centros obreros. ("Los dogmas", n 25, 1 de septiembre de 1913)

Es interesante la critica de Thiessen a Ferdinand de Lassalle. Aunque la versión posterior de la historia del socialismo lo ubica en el campo de los derrotados y expulsados por Marx del campo del socialismo, el partido alemán, y a través de él toda la Segunda Internacional, mantuvo la idolatría a quien fuera uno de los principales fundadores de la corriente en Alemania. El grupo Vorwärts de la Argentina, en el que militara Lallemant, presidía sus reuniones con retratos de Marx y de Lassalle; y el Partido Socialista de Justo, en el mismo año 1913 en que Thiessen hace sus críticas, encargaba un monumento a Ernesto Soto, promocionado en La Vanguardia (1 de mayo de 1913), cuyo epígrafe era elocuente: "Marx, Engels y Lassalle conduciendo al hombre hacia una vida mejor".

Las críticas que se plantean en Palabra Socialista a la politica justista van desde actitudes puntuales de los legisladores hasta cuestiones ideológicas más generales, en la que se incluye la labor periodística del diario oficial La Vanguardia.

Ya desde los primeros números se critica el proyecto de ley de Enrique Dickmann de reformar las leyes de residencia y de defensa social. Para Palabra Socialista, un diputado obrero debe proponer la derogación lisa y llana de ambas leyes, y no su modificación. También critican una propuesta de Repetto de asignar una partida presupuestaria para mejorar el estado edilicio de cárceles y cuarteles. Se critica también que, dentro del partido, no se le otorguen derechos partidarios a los extranjeros, por el hecho de no tener ciudadania argentina. Incluso algunos miembros del grupo tratan de forzar en un congreso, infructuosamente, el ingreso de delegados "no ciudadanos" que son rechazados. Como insinúa Casaretto en un artículo, eso no sólo deja a los extranjeros fuera del partido sino, por lógica, también a las mujeres.

Las críticas no apuntan solamente a la línea general del partido, sino también a algunas personalidades destacadas. En diversos números se cuestiona el nacionalismo de Manuel Ugarte, se ironiza sobre el pintoresquismo de Alfredo Palacios, el abstencionismo de José Ingenieros, las infulas filosóficas de Esteban Dagnino o el reformismo parlamentario de Dickmann o de Repetto. Juan B. Justo se salva de los sarcasmos, pero no de las críticas. En el no 13 (15 de enero de 1913) aparecen dos artículos (de Elias Leyboff y de Luis Miranda, futuro dirigente del Partido Comunista) cuestionando seriamente un texto de Justo aparecido en $L a$ Vanguardia. El artículo de Miranda se titula "Revisionismo y marxismo".

Enrique Del Valle Iberlucea es aplaudido en el congreso de 1912 
porque tiene algunos gestos de apoyo a la minoría de izquierda (incluso reproducen algún texto suyo en $\mathrm{el}^{\circ} 12$ ), pero al año siguiente es elegido senador por la Capital Federal y abandona toda veleidad izquierdista. Comentando el discurso del $1^{\circ}$ de mayo de 1913 , dice un articulista que firma Argos:

Del Valle Iberlucea estuvo desconocido. A diferencia de otros años, no citó ni a Marx, ni a la Internacional, ni a la bandera roja... Después de una breve introducción en la que habló del ejército libertador que cruzó los Andes para libertar a sus naciones, y de la patria (Argentina, probablemente), expuso los proyectos que piensa presentar al parlamento.

La crítica se extiende a otros oradores y se concluye que el acto se ha desaprovechado: "Sólo ha sido útil para la política simplemente radical del titulado organismo político del proletariado argentino, es decir del partido socialista". Afirmar que el Partido Socialista tiene una politica "simplemente radical" y que su pretendida orientación proletaria no es más que un título autoimpuesto y falso implica para los miembros de este sector de izquierda ubicarse al borde de una escisión.

Importa destacar también una defensa del materialismo histórico, frente a un ataque que publica Enrique Dickmann en La Vanguardia del 12 de diciembre de 1913. Dos artículos se dedican a combatir la tesis de Dickmann, uno de Manuel Pereyra ( ${ }^{\circ}$ 32, 15 de diciembre de 1913, es decir sólo tres días después de que aparece el artículo de Dickmann) y otro de Elías Leyboff ( $\mathrm{n}^{\circ} 33,15$ de enero de 1914). Según este último, Dickmann define el materialismo histórico como un materialismo grosero que sólo considera los avances técnicos y productivos y desprecia los aspectos sentimentales y éticos del ser humano. Leyboff niega esto y afirma que es la misma crítica que hacen los idealistas, tergiversando el marxismo. El análisis histórico-económico sirve de base (subrayado en el original) para el análisis de la sociedad en su conjunto. Nadie pretende analizar una obra de arte a partir de la economía. Para Dickmann, sigue Leyboff, todo se reduce a la Sinceridad y la Ética. Leyboff niega que la prédica moral sirva para modificar el estado de cosas, y si se explican los delitos por la situación económica no significa que los delitos no existan o que haya un componente psicológico o subjetivo. La economía es la base de los otros comportamientos, nada más, pero nada menos. Los socialistas, concluye, tienen una ética, y es "la solidaridad proletaria de clase", la educación para la lucha, con lo cual acusa indirectamente a Dickmann de basarse en una ética no sólo idealista sino, sobre todo, individualista.

Otro planteo importante se da en torno a la lucha política. Nueva- 
mente debemos citar a Elias Leyboff, en su artículo "Socialismo y lucha política" (n 37, 15 de marzo de 1914):

En los países atrasados, en donde la burguesía no ha conquistado su hegemonía política, el partido socialista, naciente o ya formado, agita el problema de los limites entre las aspiraciones socialistas y los derechos politicos a conquistar.

Es decir que el socialismo, en un país atrasado como la Argentina, debe trabajar en el limite entre los dos tipos de consignas (obreras y democráticas) y eso sirve como sistema de depuración: quienes sólo se interesan por los aspectos revolucionarios, abandonarán el partido para pasarse a las filas del anarquismo. Quienes sólo se interesen por las consignas democráticas, se harán liberales. Pero "el llamado partido socialista argentino considera la propaganda y la organización socialista prematura e incompatible con las aspiraciones prácticas del momento". Es decir que el partido de Justo abandona las consignas obreras y sólo se interesa por las reivindicaciones democráticas. De esa manera, no se hace una crítica del capitalismo, sino que se busca reformarlo.

Para Leyboff, el verdadero socialismo "ataca la forma de producción y de distribución capitalista", "es incompatible con el militarismo", "no admite restricciones de las libertades públicas". "El socialismo es incompatible con las fronteras territoriales establecidas por el capital", "es incompatible con la forma del matrimonio moderno", "es incompatible con la constitución política del país". Su pronóstico sobre la democratización del Partido Socialista anticipa la constitución del futuro Partido Comunista: "Tal vez el crecimiento rápido de un partido con un programa de radicalismo burgués pondrá a la orden del día la formación de un verdadero partido socialista obrero en este país". ${ }^{2}$ Frente a cualquier duda que generara esta frase, el "partido con un programa de radicalismo burgués" es el PS de Justo, y el "crecimiento rápido" apunta a los éxitos que ha tenido el socialismo en las elecciones de 1912 y 1913. El "verdadero partido socialista" que pronostica Leyboff parece tener su acta de nacimiento en enero de 1918, con la conformación del Partido Socialista Internacional.

\section{Quiénes son los que escriben}

Haremos una caracterización de los diferentes redactores o firman-

2. Obsérvese en este debate el eco de aquel otro de 1908 entre Justo y Ferri (en el que también participó Leyboff), expuesto por Carlos Herrera en otro artículo de este dossier. 
tes de artículos que se publican como colaboraciones. Las indicaciones pueden ser tomadas como provisorias y completadas con investigaciones de mayor alcance temporal.

Ya hemos anticipado que buena parte del grupo que se nuclea en Palabra Socialista o en el Centro Carlos Marx será el creador del Partido Socialista Internacional en 1918 (desde 1920, Partido Comunista). Entre ellos, es decir aquellos que se mantendrán en una crítica indeclinable a las posiciones democráticas del PS, se encuentran Juan Ferlini Guillán, Amadeo Zeme, Atilio Alberini (los dos últimos, luego del PSI y del PC, formaron parte del partido de Penelón en 1927), Pedro Zibecchi (que también firma con el seudónimo de Ernesto Radamés), Emilio González Mellén, Ramiro Blanco (de Rosario), Luis Miranda, José F. Grosso, Julián Ducasse.

José Penelón, en cambio, casi no figura en Palabra Socialista. Participa en la cooperativa inicial que sostiene el periódico, pero no hay colaboraciones suyas firmadas. Tampoco se lo menciona en la conformación del Centro Carlos Marx, en 1913. La redacción levanta un artículo que aparece en Humanidad Nueva, pero en ocasión del XI Congreso del PS de 1912 critican la actitud de Penelón de abandonar el congreso y renunciar al partido. A partir de ese momento ya no es nombrado. Evidentemente la redacción lo considera dentro del amplio sector de opositores a la dirección, pero no parece tener en estos dos años un papel central en su conformación.

Otro de los más asiduos colaboradores del quincenario, y en varias ocasiones secretario de redacción, es Martín Casaretto, quien en la crisis de 1918 opta por permanecer en las filas del socialismo justista y en los años 30 escribe una historia del movimiento obrero argentino. Casaretto parecía ser, desde los primeros números, el principal vocero de Palabra Socialista, pero durante 1913 se ausenta de Buenos Aires por motivos laborales y, aunque regresa, desde ese momento parece tener un rol de segundo orden. Otro de los colaboradores que permanece en el PS es Fernando De Andreis (hijo de un dirigente del Partido Socialista), quien a fines de la década siguiente será diputado y se irá con Antonio De Tomaso a formar el Partido Socialista Independiente.

A otras firmas destacadas de la publicación les perdemos el rastro: uno de ellos es Pablo Chanussot, que traduce del francés varios textos y posiblemente todos los escritos de Elías Leyboff y que actúa como redactor principal durante algunos números. Otro es Renato Cozzi, presente en la cooperativa fundacional del quincenario, en la redacción del diario, delegado al congreso del PS de 1913, orador frecuente en los actos de la izquierda juvenil y miembro del Centro Carlos Marx. Algún otro miembro del grupo sigue un camino académico: Alejandro Jascalevich se va a estudiar con John Dewey en Estados Unidos y cuando 
regrese a la Argentina en 1919 se dedicará a las traducciones y a la filosofia, alejado del socialismo.

Elias Leyboff merece un párrafo aparte. Sus escritos figuran entre los más elaborados y extensos de la revista. Suelen ser colocados en primero o segundo lugar y en ciertos temas centrales la revista parece cederle el lugar para que encabece las críticas a la dirección socialista. Gracias a que es atacado por La Vanguardia, el quincenario publica un artículo en su defensa y nos enteramos de algunas circunstancias de su vida $\left(\mathrm{n}^{\circ} 35,15\right.$ de febrero de 1914).

Nació en el imperio ruso, en Ekaterinoslav (hoy Dniepropetrovsk, Ucrania), comenzó a estudiar medicina en Kiev y allí leyó a Marx y a Plejanov. Junto a otros estudiantes hacian propaganda socialista en las minas de Ekaterinoslav hasta que los descubrió la policía zarista y deportó a la mayoría. Leyboff, junto a otros, se exilió en Francia y terminó sus estudios de medicina en Montpellier, haciendo luego un doctorado en París. En Lyon se unió al Partido Socialista francés, sección Jules Guesde. Colaboró con los exiliados rusos y publicó artículos en el diario socialista de Ekaterinoslav Viestnik Yuga, con el seudónimo de Roníky, hasta 1908, cuando se traslada a la Argentina. Aquí llega con pocos recursos, mujer e hijos, sin saber el idioma, y se instala en Rosario del Tala (centro de Entre Ríos), para convertirse en médico de las colonias judias de la zona. Al año de llegar envia a la Revista Socialista Internacional un artículo de crítica a la política del socialismo argentino, titulado "Carta al doctor Justo". Por esta carta lo conocen los jóvenes de izquierda y se comunican con él cuando comienzan a editar el periódico.

Leyboff evidencia un gran conocimiento del marxismo y de las circunstancias que rodean la construcción del socialismo en Europa. Conoce de primera mano lo que sucede en Rusia, en Francia y en Bélgica. Al igual que los redactores de Palabra Socialista, se ubica en la defensa del marxismo y aboga por la conformación de un socialismo obrerista. Aunque no cree en las posibilidades de las reformas parlamentarias, su posición sobre los métodos de lucha se acercan más a la izquierda de la socialdemocracia alemana que al futuro bolchevismo: el socialismo, piensa Leyboff, debe desarrollar métodos de lucha pacíficos. La violencia está en el Estado y es producto de la reacción del capital frente a los métodos de lucha pacíficos de la clase obrera. Revolucionario pero antijacobino, considera que el capitalismo exacerba las contradicciones económicas y políticas hasta que se vuelven insoportables para la población, pero no es el proletariado sino la burguesía la que toma la iniciativa de reaccionar con violencia ("Política de hechos pequeños o politica socialista", $\mathrm{n}^{\circ} 13,15$ de enero de 1913). Desconocemos el destino ulterior de este médico rural, que a través de la correspondencia intentó mantenerse vinculado al movimiento obrero internacional. 
Es interesante también observar las relaciones entre Palabra Socialista y la revista Humanidad Nueva. Esta publicación, continuadora de la recién nombrada Revista Socialista Internacional, en la que tuvieron un papel central Enrique Del Valle Iberlucea y Alicia Moreau, incluia en su redacción a miembros de Palabra Socialista como Renato Cozzi, Pedro Zibecchi y Guido A. Cartey. También Fernando de Andreis, participante ocasional, es presentado como ex director de Humanidad Nueva. Como ya comentamos antes, el único artículo que aparece firmado por Penelón fue publicado originalmente en esa revista-libro de Del Valle Iberlucea. Como se sabe, este último exhibió durante toda su militancia cierta inclinación al socialismo marxista (Corbière, 1987; Marianetti, 1972) y, a pesar de las críticas que recibe en Palabra Socialista, también parece justificado que algunos militantes participaran de los dos ámbitos editoriales.

Cerramos el registro de los colaboradores de la publicación con dos casos que van más allá de la producción de textos. Uno es Ramiro Blanco, quien también firma Errebeyese, militante socialista asturiano, que llega a la Argentina en 1911 y ya en 1912 se conecta con la izquierda del socialismo. Constructor del partido y de la juventud del socialismo en Rosario, seguirá vinculado al grupo y se constituirá en uno de los fundadores del Partido Socialista Internacional. El otro es Cornelio Thiessen (su apellido es deformado constantemente en los primeros números, hasta que se estabiliza), dirigente en Tolosa y La Plata. Cuando se constituya el Movimiento Juvenil Socialista, en 1914, colaborará en forma decidida con la campaña antimilitarista. Muere en 1916 y la juventud en homenaje publica una conferencia suya en forma de folleto (Thiessen, 1917). Como ya hemos mencionado, evidencia un gran conocimiento de inglés, francés y sobre todo alemán, traduciendo textos íntegros o citando a los clásicos desde su lengua original, pero fundamentalmente es quien vincula al sector izquierdista con las secciones rebeldes de La Plata y uno de los principales animadores del despertar juvenil.

\section{Balance y proyecciones}

Si bien el grupo de redacción de Palabra Socialista tiene un fuerte enfrentamiento con la dirección partidaria, a la que tilda de practicista y reformista, el grado de elaboración de una doctrina alternativa y verdaderamente diferente dista de haber sido completamente elaborada. Lo que une al grupo no es una visión homogénea sobre qué hacer, sino un rechazo decidido a las formas burguesas de la politica de la dirección del PS. Si bien esta característica puede observarse en cualquier grupo, consolidado o no (el porvenir aparece diseñado en una multitud 
de posibilidades, pero sólo una prevalecerá ante los embates de la realidad), en el periódico que estudiamos resulta más acusado todavía el momento negativo de su conformación y son más notorias las aristas contradictorias de su proyección.

Para ejemplo, basta ver la politica con respecto al movimiento obrero. Si bien le critican al socialismo el abandono de larga data de una política sindical coherente, el grado de inserción en los lugares de trabajo o el de elaboración de una política diferente en lo gremial no pasa de ser una declaración de principios. Eso no quiere decir que sus diferentes integrantes estén lejos de la militancia sindical, sino que no hay una elaboración específica del problema a lo largo de las páginas del quincenario, más allá de la reivindicación de diferentes luchas o acciones puntuales de la clase, o de las criticas específicas que se descargan, sobre todo al sindicalismo revolucionario. El debate con esta última corriente se desarrollará más adelante, sobre todo entre 1916 y 1917 , en las páginas de La Vanguardia (Camarero y Schneider, 1991) y allí se evidenciará el entendimiento táctico entre la nueva dirección de la FORA y la dirección justista del socialismo argentino, ambos en contra de las posturas de Penelón.

El tema del Comité de Propaganda Gremial, por ejemplo, es un tema que apenas es rozado por Palabra Socialista. Por supuesto se apoya su constitución, pero no se hace eje en ese problema. El CPG fue planteado en el congreso partidario de 1911, pero recién empezó a funcionar a mediados de 1912. Según Palabra Socialista (nº 11, 15 de diciembre de 1912), "a pesar de su poca existencia (6 meses), de los escasos recursos de que dispuso, de la negación de su concurso por parte de afiliados y secretarios de Centros y de la falta de tacto para su nombramiento e integración, por desconocimiento y falta de interés por parte del Comité Ejecutivo que cesó, ha realizado obra buena, constituyendo varias organizaciones obreras". El CPG es boicoteado por el partido y se disuelve tras la renuncia de Penelón. No se reconstituirá hasta mayo de 1914, es decir, coincidentemente con el cierre del quincenario. Recién en ese momento la izquierda marxista entenderá que su principal campo de acción debe ubicarse en el ámbito de la lucha sindical, alrededor del comité dirigido por Penelón.

Otro punto en donde se observan las vacilaciones entre la política que se abandona y la que se adoptará es en la cuestión de los métodos de lucha. Si bien hay una crítica cerrada al parlamentarismo de Repetto, Dickmann y Justo, en nombre de la concepción de la lucha de clases como motor de la historia, no se vislumbra claridad en cuanto a las formas de desarrollo de esas luchas obreras. El artículo citado de Leyboff es en ese sentido característico: la insistencia en la idea declaradamente antijacobina de que el movimiento socialista debe desarrollar 
una lucha con métodos pacíficos, dejándole a la burguesía la iniciativa de la violencia, está todavía más cerca de la izquierda socialdemócrata de fines del siglo XIX que del bolchevismo de 1917.

Agregamos dos elementos que, aunque ya señalados, no dejan de marcar diferencias de apreciación que pudieron tener alguna incidencia en los hechos posteriores. Uno está marcado por la inclusión o no de Ferdinand de Lassalle dentro del panteón de guías del socialismo. El otro es la mencionada idealización del socialismo europeo, visto como un cuerpo unificado detrás de las ideas de Marx. En ambos casos, Thiessen y otros se ubicaron en una crítica más matizada, y no puede dejar de observarse que todas esas diferencias apuntan a una reelaboración de las herencias de la socialdemocracia alemana en un sentido más de izquierda.

La creación de otro partido se siente en el aire, pero todavía no ha llegado el momento, y el hecho de que el grupo siga siendo minoritario en los congresos es el sintoma de que una ruptura sería vivida como temprana. Todavía en 1912, cuando Penelón decide renunciar al PS, el redactor anónimo que hace el comentario del congreso dice: "Creemos prematura y perjudicial para la causa del proletariado una escisión en nuestras filas" ("Notas del XI Congreso", n 9, 15 de noviembre de 1912). Así puede pensarse que la victoria del ala izquierda unos años después, en el congreso extraordinario de abril de 1917, permitió acelerar los tiempos.

Otro elemento político desarrollado por el grupo, y alentado claramente por el quincenario, es el movimiento juvenil. Esto sólo se da en los últimos momentos. En el n ${ }^{\circ} 36$ (1 de marzo de 1914) se anuncia en un lugar destacado el nacimiento del Movimiento Juvenil Socialista. Todos los participantes del grupo conforman el MJS y son oradores en sus actos. Se insiste en que la juventud debe ocupar un lugar preferencial en la campaña electoral y se le solicita a la dirección del partido que se acepten oradores por la juventud. Ante la negativa, el movimiento desarrolla sus propios actos de propaganda, donde hablarán Martín Casaretto, Jaime López, José F. Grosso, Gualterio Mattioli, Renato D. Cozzi, Pedro Zibecchi, Manuel M. López, Fernando De Andreis, Alberto Carcagno, Luis M. López y Emilio González, es decir, la mayoría de los militantes vinculados al quincenario. El ala izquierda del partido encuentra en los jóvenes un gran aliado, fundamentalmente a partir del rechazo a las guerras y al enrolamiento obligatorio.

Este movimiento juvenil seguirá existiendo más allá de la extinción de Palabra Socialista y en abril de 1916 dará origen a una revista, Adelante, que seguirá apareciendo hasta enero de 1918, entroncando su existencia con la del naciente partido marxista dirigido por Penelón. La revista Adelante, de características gráficas muy similares a Palabra 
Socialista, estará dirigida por Juan Ferlini, también secretario de redacción del quincenario que analizamos.

Lo que parece faltar, en Palabra Socialista, es un dirigente con una envergadura intelectual mayor. Ese papel, que más adelante será ocupado por José F. Penelón y, sobre todo, por el chileno Luis Emilio Recabarren (quizás el motor más importante que tuvo la escisión de 1918), todavía se echa en falta en la publicación de 1912. Elías Leyboff parece llenar ese papel, pero no tiene un rol militante en el grupo, sino más bien el de un intelectual a la distancia que vincula la crítica del ala izquierda a la dirección "simplemente radical" del PS con la experiencia del socialismo europeo y el acceso directo a los clásicos. Ningún otro colaborador exhibe el desarrollo teórico de Leyboff (no queremos dejar de mencionar los ocasionales artículos de Cornelio Thiessen y de Manuel Pereyra), pero Leyboff, a su vez, no tiene un contacto con el movimiento de la lucha de clases de la Argentina y quizás ni siquiera conoce bien la lengua castellana.

Penelón no participa del grupo, y recién va a tener un papel central a partir de la conformación, como ya dijimos, en mayo de 1914 del Comité de Propaganda Gremial. Martín Casaretto, Pedro Zibecchi, Amadeo Zeme, Pablo Chanussot no logran dar con la fisonomía de dirigente del grupo. Juan Ferlini parece más un intelectual y un buen escritor que un guía político. En definitiva, lo que se observa es más una tendencia a la cooperación política que una organización estructurada. La llegada al país de Luis Emilio Recabarren, el liderazgo y la militancia que desarrolla el Comité de Propaganda Gremial (abriendo frentes obreros y colaborando en los conflictos) y la indignación de la juventud con respecto al tema de la guerra mundial serán los catalizadores que van a dar pie a la conformación de la escisión de 1918 y la creación del Partido Socialista Internacional.

\section{¿Por qué se cierra Palabra Socialista?}

En los últimos números, nada deja entrever una decadencia económica o política de la publicación: se sigue editando hasta último momento con sus ocho páginas quincenales, como en los últimos dos años. No se registran debates ni polémicas que pongan en peligro la unidad de criterio. Descartamos una vinculación con el comienzo de la primera Guerra Mundial: hasta tres meses después del último número no hay una necesidad de toma de posición que afecte la cohesión ideológica del ala izquierda del socialismo. Todos coinciden con la que, hasta ese momento, es la posición "oficial" de los partidos socialistas europeos: huelga general obrera para derrotar la posible guerra.

La desaparición del quincenario (y la hipótesis que aquí manejamos 
depende exclusivamente de considerar que el $\mathrm{n}^{\circ} 40$, del 15 de mayo de 1914, es efectivamente el último) coincide con un suceso que pudo haber actuado como catalizador de diferencias: el XII Congreso del Partido Socialista, desarrollado en Rosario entre el 22 y el 24 de mayo. En el mismo se observa una derrota profunda del sector izquierdista: el informe del Comité Ejecutivo es aprobado por amplia mayoría en todos sus puntos, el control que la dirección justista realiza en la organización se evidencia fuerte y sin fisuras. El ala izquierda del partido puede haber experimentado un duro golpe en sus filas. De hecho, el número 41 debia ofrecer a los lectores un balance de la reunión partidaria, y esto pudo haber despertado desentendimientos imposibles de resolver.

El sector que se agrupa en Palabra Socialista apenas está representado en las delegaciones al congreso: Zibecchi y Casaretto son los que participan mayormente en los debates; también figuran Renato Cozzi, Guido Cartey, José F. Grosso, José Vescovo y algunos pocos nombres más que se ubicarán en el ala izquierda con posterioridad (La Vanguardia, 28 y 29 de mayo de 1914). En el marco de un centenar de delegados, este sector sólo cuenta con una docena de votos.

Entre las diversas discusiones que se suscitan en la asamblea, el punto más polémico es una propuesta de la dirección para retirar del programa partidario la crítica al trabajo a destajo: vale la pena detallar cómo se origina.

El viejo militante y fundador del partido Miguel Pizza es dueño de una fábrica metalúrgica (Haupt y Pizza) donde a los trabajadores se les paga por pieza. ${ }^{3}$ Los obreros bronceros desarrollan una huelga para pasar del pago a destajo al pago diario y varios centros de la Capital le exigen a la dirección del partido que sancione al propietario Pizza por violar un punto del programa que, justamente, rechaza esa forma de pago. Después de algunas evasivas, el CE le encarga al militante Pedro Porcel que realice un informe de los hechos, pero éste será fuertemente negativo con respecto al pago por pieza y a las actitudes del empresario. La dirección partidaria desconoce ese informe, y en vez de sancionar a Pizza decide proponerle al congreso que se saque del programa el rechazo al trabajo a destajo.

Ya en el congreso, esta propuesta es atacada violentamente por el ala izquierda, que ha desarrollado una larga campaña en Palabra Socialista

3. Nicolás Repetto (1956: 32) afirma que el local de México 2070 "era propiedad del compañero Haupt, un antiguo obrero alemán, a quien se había expulsado de su país en virtud de la ley bismarckiana contra los socialistas, pero que en la Argentina se había enriquecido explotando un taller metalúrgico, cuyas utilidades invertía en la construcción de locales para el partido, las sociedades gremiales y las cooperativas, que entregaba sin cargo de alquiler a las entidades indicadas". Agradezco esta referencia a Lucas Poy. 
sobre el tema. El argumento esgrimido por el ala oficial del partido es verdaderamente llamativo: el trabajo por pieza, afirman, beneficia a los obreros más capaces, mientras que el salario por jornal lo solicitan los obreros haraganes. La aceptación de la modificación programática es sancionada finalmente por Juan B. Justo en un largo discurso, donde afirma que jamás el movimiento socialista internacional se movilizó contra el salario por pieza, y que no está demostrado que perjudique a los obreros, olvidando seguramente la traducción que él mismo había hecho veinte años antes de El capital, donde en la sexta sección Marx dedica un capítulo entero a demostrar los beneficios de esta forma de pago para el capitalista y el perjuicio para el obrero. También olvidó los reclamos obreros desde fines del siglo XIX, en la Argentina, exigiendo terminar con el pago a destajo. El discurso de Justo es coronado con una aclamación, según el diario oficial, y la propuesta es aceptada, dejando en el olvido toda sanción al burgués "socialista" Miguel Pizza. A las constantes vacilaciones teóricas del justismo, se le agregaba la tendencia a claudicar frente a las necesidades de dos dueños de fábrica, uno de los cuales era un viejo militante y dirigente del partido, y el otro un burgués benefactor a quien no convendría alterar con "pequeñeces" economicistas.

Hay que tener en cuenta que el socialismo de Justo viene de dos victorias electorales significativas en la Capital Federal, en 1912 y en 1913, gracias a las cuales Del Valle Iberlucea es elegido senador y un núcleo de dirigentes son elegidos diputados. La táctica parlamentarista parece estar rindiendo sus frutos y el ala izquierda cuenta con todos los argumentos a su favor menos uno: el éxito. El batallón de los críticos aumenta, pero cada vez es más marginado del partido. Ante esa situación, es muy probable que surgieran disidencias en cuanto a la conveniencia de seguir en la misma postura crítica y eso significará el fin de la publicación quincenal.

En este sentido, vemos que la política parlamentarista de Justo, que hacia el Centenario se mostraba poco fructífera, ahora tiene logros que exhibir, logros que tienen la virtud de entusiasmar a sus partidarios y acallar los apoyos al ala izquierda. Por añadidura, un importante referente partidario como Del Valle Iberlucea deja atrás, al menos por el momento, sus "gestos" de apoyo a la izquierda y se inscribe en los andariveles reformistas que ahora se imponen en la organización. El Partido Socialista parece cerrar así una crisis que no se mostraba como tal pero que anidaba en los continuos fracasos que hasta 1912 habian jalonado su historia. Pero ese fortalecimiento del reformismo parlamentario sería de corto alcance, pues la guerra mundial abriria nuevas fisuras entre la mayoría justista y el ala izquierda, que harian eclosión en el congreso extraordinario de abril de 1917 y, posteriormente, la creación del PSI. 
Quienes busquen rescatar un desempeño electoral ascendente, minimizarán las sucesivas crisis y fracturas que experimenta el partido de Justo (mucho más allá de la época de la que hablamos); quienes pretendan confrontar la historia del PS con el proyecto de crear un partido de la clase obrera, no podrán dejar de observar cada uno de estos tropiezos como un anticipo de su posterior dispersión y su conversión en un partido demócrata sin resabios de socialismo.

Coincidentemente con el cierre de Palabra Socialista y con el congreso de Rosario, se está conformando el Comité de Propaganda Gremial. No hemos encontrado en esos meses ninguna referencia a la creación o a la existencia del mismo en las páginas de La Vanguardia, pero su acta de constitución es reproducida en un texto de Emilio González Mellén de 1917 (citado en Camarero y Schneider, 1991: 78-97). El comité tuvo una vida muy activa y es probable que los esfuerzos del sector marxista del partido, ya sin una publicación central, se haya volcado a los trabajos sindicales ahora en alianza con José F. Penelón.

Se cerraba así un capítulo en la conformación del ala izquierda del Partido Socialista, pero se abria otro, seguramente más fructifero, que se desarrollaría en los años de la Primera Guerra Mundial. Los avatares del conflicto bélico darán pie, tanto en el mundo (revolución rusa) como en la Argentina, a la consolidación de nuevas organizaciones y nuevas configuraciones políticas. Y será la lejana guerra la que dará oportunidad para que el ala izquierda del socialismo cristalice en una organización más amplia y definida, cuando se enfrente a las tendencias aliadófilas de la dirección justista. Al igual que en Europa, la traición que significó el apoyo socialdemócrata a una guerra que habian combatido hasta el momento mismo de su inicio será la oportunidad para que un sector, que denunciara desde un comienzo a la guerra como ajena a los intereses del movimiento obrero, emprendiera un camino independiente y dejara de lado el reformismo y el parlamentarismo del Partido Socialista.

\section{Bibliografia}

Bilsky, Edgardo (1984), La Semana Trágica, Buenos Aires: CEAL.

Camarero, Hernán (2007), A la conquista de la clase obrera. Los comunistas y el mundo del trabajo en la Argentina, 1920-1935, Buenos Aires: Siglo XXI.

Camarero, Hernán y Alejandro Schneider (1991), La polémica Penelón-Marotta (marxismo y sindicalismo soreliano, 1912-1918), Buenos Aires: CEAL.

Campione, Daniel (2005), El comunismo en Argentina. Sus primeros pasos, Buenos Aires: Ediciones del CCC.

Cole, G.D.H. (1986), Historia del pensamiento socialista, tomo III, México: FCE. 
Corbière, Emilio (1984), Orígenes del comunismo argentino (El Partido Socialista Internacional), Buenos Aires: CEAL.

- (1987), El marxismo de Enrique Del Valle Iberlucea, Buenos Aires: CEAL.

Del Campo, Hugo (1983), Sindicalismo y peronismo. Los comienzos de un vinculo perdurable, Buenos Aires: CLACSO.

Dỉaz, Hernán (2008), "Introducción”, a Ramón Suárez Picallo, Años de formación política. Selección de textos (1916-1931), Buenos Aires: Alborada.

Haupt, Georges (1978), L'Internazionale Socialista dalla Comune a Lenin, Turin: Einaudi.

Jeifets, Victor y Lazar Jeifets (2014), "La Internacional Comunista y la izquierda argentina: primeros encuentros y desencuentros", Archivos n ${ }^{\circ}$ 5, septiembre.

Joll, James (1976), La II Internacional. Movimiento obrero 1889-1914, Barcelona: Icaria.

Marianetti, Benito (1972), Enrique Del Valle Iberlucea. Una honesta conducta frente a la revolución rusa, Buenos Aires: Sílaba.

Oddone, Jacinto (1934), Historia del socialismo argentino, Buenos Aires: La Vanguardia.

Partido Socialista Internacional (1919), "Historia del socialismo marxista en Argentina", en Daniel Campione (2005), pp. 61-112.

Repetto, Nicolás (1956), Mi paso por la politica. De Roca a Yrigoyen, Buenos Aires: Santiago Rueda.

Tarcus, Horacio (2007), Diccionario biográfico de la izquierda argentina, Buenos Aires, Emecé.

Thiessen, Cornelio (1917), El militarismo y las juventudes socialistas, Buenos Aires: Juventud Socialista Cornelio Thiessen, prólogo de Jaime López.

Viguera, Aníbal (1991), "Participación electoral y prácticas políticas de los sectores populares en Buenos Aires, 1912-1922", Entrepasados, año I, $\mathrm{n}^{\mathrm{o}} 1$, Buenos Aires.

Titulo: The newspaper Palabra Socialista (1912-1914) and the beginnings of dissent in the Argentine marxist socialism

Resumen: El texto aborda el análisis del periódico Palabra Socialista, primer órgano del ala izquierda del Partido Socialista que desembocará en 1918 en la creación del Partido Socialista Internacional (luego Partido Comunista). Se relevan aspectos técnicos, las principales ideas programáticas, se traza un cuadro de los principales miembros del grupo y se realiza un balance de su participación en el ámbito de la política argentina entre 1912 y 1914.

Palabras clave: socialismo - orígenes del marxismo argentino - Centenario

Abstract: The text deals with the analysis of Palabra Socialista, first newspaper of the left wing of the Socialist Party that will result in 1918 in the creation of 
the International Socialist Party (then Communist Party). Technical aspects are relieved, the main programmatic ideas, a picture of the main members of the group plotted and balance of their participation in the field of Argentine politics between 1912 and 1914 was performed.

Keywords: socialism - origins of the Argentine marxism - Centenario

Recepción: 9 de noviembre de 2014. Aprobación: 28 de febrero de 2015. 